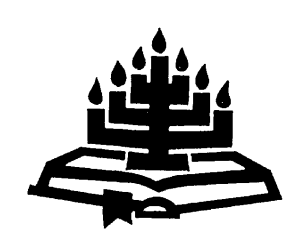

\title{
'n Ondersoek na die teologiese boodskap en prediking van Psalm 117
}

\author{
S.D. Snyman \\ Departement Ou Testament \\ Universiteit van die Vrystaat \\ BLOEMFONTEIN \\ E-pos: snymansd@ufs.ac.za
}

\section{Abstract \\ An investigation into the theological message and preaching of Psalm 117}

Psalm 117 is at the same a well-known and an unknown psalm. It is well-known as the shortest psalm in the Psalter, but there actually is remarkable little theological reflection on the psalm. To answer the question about the theological message of the psalm, it is subjected to an exegetical investigation giving attention to matters such as the extent of the psalm, text-critical questions, structural features, literary genre, "Sitz im Leben", dating, the use of traditional material, et cetera. The exegetical details lead to a theological conclusion where it was found that the steadfast love and faithfulness of Yahweh experienced by his people in history serve as the reason why foreign nations are called upon to praise Him. The psalm probably originated in an exilic situation, reflects on the past and motivates people towards a future where Yahweh's love and faithfulness will once again be experienced by his people.

\section{Opsomming}

\section{'n Ondersoek na die teologiese boodskap en prediking van Psalm 117}

Psalm 117 is tegelykertyd 'n bekende en onbekende psalm. Hierdie psalm is bekend as die kortste in die boek van die Psalms, maar daar is min teologiese refleksie op die psalm. Om die vraag na die teologiese boodskap van die psalm te beantwoord, is die psalm aan 'n eksegetiese ondersoek onderwerp waarin aandag gegee word aan sake soos die omvang van die psalm, tekskritiese kwessies, strukturele kenmerke, die literêre genre, "Sitz im Leben", datering, die gebruik van tradisiemateriaal, ensovoorts. Die eksegetiese detail het tot 'n teo- 
logiese gevolgtrekking gelei dat die (verbonds)liefde en trou van Jahwe wat die volk in die verlede ervaar het, die rede is waarom vreemde volke en nasies tot lof aan Jahwe opgeroep word. Die psalm het waarskynlik in die ballingskap ontstaan, reflekteer op die verlede en dien as motivering vir die toekoms wanneer die (verbonds)liefde en trou van Jahwe weer ervaar sal word.

\section{Inleiding en probleemstelling}

Psalm 117 is aan die een kant 'n welbekende psalm. Die psalm het sy bekendheid te danke aan die feit dat dit die kortste in die boek van die Psalms is. Dit maak Psalm 117 tegelykertyd ook die kortste hoofstuk in die Bybel. Dat Psalm 117 die kortste psalm is, doen egter nie afbreuk aan die waardering vir die psalm nie. Vir Dahood $(1970: 152)$ is die psalm "theologically one of the grandest". Lamparter (1959:253) maak ook 'n waarderende opmerking: "So kurz dieser kleinste unter den Psalmen ist, so gross und weit ist sein Horizont." Die Psalm is ook bekend as die Laudate Dominum-lied wat graag binne die Taize-gemeenskap gesing word. Psalm 117 is aan die ander kant egter ook 'n onbekende psalm. Dit staan by wyse van spreke in die skadu van twee reuse, naamlik Psalm 116 en Psalm 118. 'n Ondersoek na resente wetenskaplike navorsing op Psalm 117 lewer haas geen resultate op nie. Kommentare spandeer die minimum ruimte aan die psalm deur die psalm binne 'n bladsy of twee af te handel. Daar is weinig teologiese refleksie en/of vraagstelling alreeds oor die psalm gedoen.

Hierdie waarneming het die vraag laat ontstaan na die teologie en prediking van die psalm. Het Psalm 117 'n eie teologiese boodskap en kan die boodskap homileties vertolk word? Anders geformuleer: Wat mis ons indien Psalm 117 nie gelees word nie? Sou Psalm 117 nie maar net geïgnoreer kon word nie? Dit is die vraag wat in hierdie artikel aan die orde gestel word.

Die metodologiese weg wat gevolg word om die probleemstelling te beantwoord, is om die psalm eksegeties na te gaan, die teologiese boodskap daarvan te peil na aanleiding van die eksegese en om dan enkele hermeneutiese en homiletiese riglyne te gee wat as rigtingwysers vir die prediking van die psalm sou kon dien. 


\section{2. 'n Eksegetiese ondersoek van Psalm 117}

\subsection{Die teks van Psalm 117}

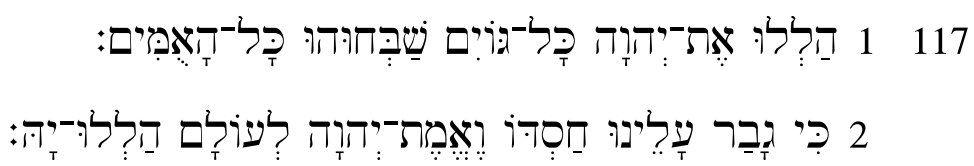

(Biblia Hebraica Stuttgartensia, 1990.)

'n Eksegetiese ondersoek van 'n teks begin by die lees van die teks, aanvanklik in die taal waarin die ondersoeker tuis is. Die lees van ander vertalings is ook verhelderend in die sin dat verskille tussen vertalings aan die lig kom. Uiteindelik moet die teks ook in die oorspronklike taal gelees word.

In die 1933/1953-vertaling van die Bybel in Afrikaans is Psalm 117 soos volg vertaal:

Loof die Here, alle nasies! Prys Hom alle volke!

Want sy goedertierenheid is geweldig oor ons, en die trou van

die Here is tot in ewigheid. Halleluja!

Die 1983-vertaling van Psalm 117 lui só:

Prys die Here, alle nasies, loof Hom alle volke, want sy liefde vir ons is sterk, aan die trou van die Here is daar geen einde nie!

Prys die Here!

Die Nuwe Lewende Vertaling van die Bybel (2006) vertaal Psalm 117 soos volg:

Loof die Here, al die nasies.

Prys Hom, alle volke.

Want sy liefde is groot oor ons;

Die trou van die Here bly vir altyd.

Prys die Here!

Dit is ook nuttig om 'n paar Engelse vertalings van die psalm na te gaan. Die New Revised Standard Version se vertaling lyk só:

${ }^{1}$ Praise the Lord, all you nations!

Extol him, all you peoples!

${ }^{2}$ For great is his steadfast love toward us, and the faithfulness of the Lord endures forever.

Praise the Lord!

Die vertaling van die New Living Translation lees soos volg: 
Praise the Lord, all you nations. Praise him, all you people of the earth. For he loves us with unfailing love; the faithfulness of the Lord endures forever. Praise the Lord!

In 'n publikasie het Jeremias (2004:95) ook 'n vertaling van Psalm 117 gemaak:

Praise Yahweh, all nations, extol him, all you peoples, because his loyal love has towered over us and Yahweh's faithfulness is everlasting. Halleluja.

Die werkwoord שבח in die Pi'el imperatief soos wat hier die geval is, het die betekenis van loof of in Engels praise, laud, commend of congratulate. Die werkwoord גבר wat in vers 2 aangetref word se betekenis word weergegee met geweldig (1933/1953-vertaling), sterk (1983-vertaling), groot (Nuwe Lewende Vertaling), of in Engels strong of mighty.

Die nasies, as vertaling van gojim (미), word gewoonlik verstaan as 'n verwysing na heidense of minstens nie-lsraelitiese nasies buite Juda/Israel. In die geval van Psalm 117 is dit waarskynlik (soos later

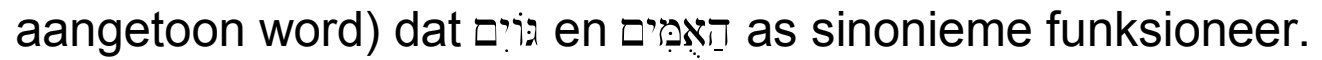

Die redegewende partikel $k i(כ)$ aan die begin van vers 2 is belangrik. Die ki- (כ) partikel lei naamlik die rede in vir die oproep na die nasies en die volke om Jahwe te prys en te loof. Die redes wat gegee word handel oor die hesed en emet van Jahwe aan ons, die volk van die Here.

Die konsepte hesed (אחמקת) en emet funksioneer as prominente begrippe in die psalm. Hierdie twee begippe word dikwels in die $\mathrm{Ou}$ Testament as 'n woordpaar gevind (Gen. 24:27, 49; 32:11; 47:29; Eks. 34:6; Jos. 2:14; 2 Sam. 2:6; 15:20, maar veral in Ps. 25:10; $40: 11$, 12; 57:4; 61:8; 85:11; 86:15; 89:15; 115:1; 138:2). Hesed (חס्र) funksioneer veral as teologiese begrip. Dit druk 'n verhouding uit of veronderstel een waar die regte en verantwoordelikhede van die betrokke partye (man:vrou, ouer:kind, regeerder:onderdaan) respekteer word. Wanneer die begrip in terme van die verhouding tussen God en sy volk funksioneer, word dit gesien as 'n begrip wat in 'n verbondsverhouding tuis is (Stoebe, 1971:600-610). Wanneer die begrip emet (يאֶ) gebruik word in terme van die verhouding tussen God en sy volk, gee dit die gedagte van "vertroue", "trou" "betroubaarheid" en "getrouheid" weer. God is die Een wat absoluut vertrou kan word as die "getroue" en "betroubare" God (Wildberger, 
1971:202-210). Om Jahwe se hulp te ervaar, is om sy betroubaarheid te ervaar en daarom kan Hy vertrou word. Die trou van Jahwe wat vir altyd duur, dui waarskynlik op 'n onbepaalde lang tyd, 'n tyd verby die horison. Dus, verder as wat 'n mens kan sien (vgl. Anderson, 1972:796).

\subsection{Psalm 117 as afsonderlike eenheid?}

'n Voor die hand liggende vraag, veral in die geval van 'n kort eenheid soos Psalm 117, is na die omvang van die psalm. Waar begin en waar eindig die psalm? In die geval van Psalm 117 is die antwoord op hierdie vraag nie sonder meer 'n uitgemaakte saak nie. Daar is gevalle in die Psalmboek waar die afbakening van die psalms nie sonder probleme is nie (Ps. 1 en 2) of waar twee Psalms eintlik as een psalm verstaan moet word (Ps. 9 en 10; 42 en 43; 111 en 112). In die geval van Psalm 117 is daar Hebreeuse manuskripte wat die psalm lees as behorende óf tot Psalm 116, óf tot Psalm 118. Psalm 117 word dus gelees as óf die einde van Psalm 116 (Schmidt, Engnell, Gunkel; vgl. Allen, 1983:117), óf as die begin van Psalm 118. Daar is goeie redes vir albei hierdie moontlikhede. Psalm 117 het nie 'n opskrif nie en kan daarom inderdaad gesien word as die slot van Psalm 116. Psalm 118 het ook nie 'n opskrif nie, wat die moontlikheid open dat Psalm 118 eintlik met Psalm 117

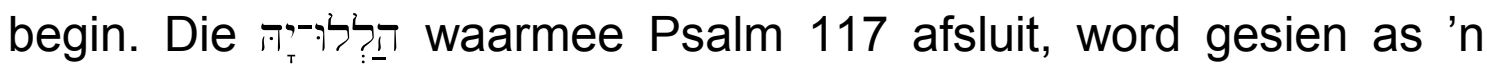
geval van dittografie van Psalm 116:19 se slotgedeelte. Hieruit word die afleiding gemaak dat Psalm 117 as die begin van Psalm 118 gelees moet word.

Daar is egter ook voldoende argumente om Psalm 117 as 'n afsonderlike psalm in eie reg te handhaaf onafhanklik van Psalm 116 of Psalm 118. Psalm 116 sluit met 'n oproep om die Here te loof, terwyl Psalm 117 met dieselfde oproep open. Die slotwoorde van Psalm 116 is egter nie presies dieselfde as die woorde waarmee Psalm 117 open nie. Psalm 116 sluit met הלילוּיָיזי 117

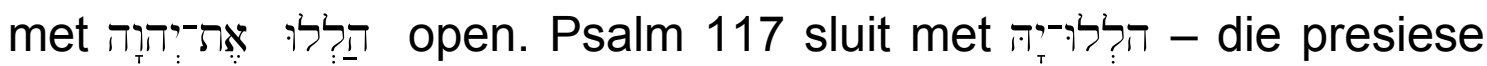
woorde waarmee Psalm 116 sluit. Wanneer die twee Psalms nader met mekaar vergelyk word, wys geleerdes gewoonlik op die aard en karakter van die twee psalms wat van mekaar verskil (Weiser, 1975:721; Kraus, 1972:798; Anderson, 1972:796).

Die refreinvers in Psalm 118, tesame met die oproep om dank aan Jahwe uit te spreek vir sy goedheid, is 'n aanduiding daarvan dat Psalm 118 ook opvallend verskil in terme van die aard en karakter 
van Psalm 117. In Psalm 117 is dit die trou (אֶָָת) van Jahwe wat vir altyd duur, terwyl dit in Psalm 118 die liefde (חיר (חי) van Jahwe is wat vir altyd duur. Dit is ook opvallend dat Psalm 118 begin en sluit met dieselfde woorde en sodoende die psalm saambind in 'n eenheid. Geleerdes het in hierdie verband ook daarop gewys dat die liturgiese inleiding van Psalm 118 versteur sal word indien Psalm 117 as die begin van Psalm 118 gelees sou word (Weiser, 1975:721).

Psalm 117 kan dus as 'n eie, onafhanklike psalm in eie reg beskou word. Interessant genoeg is die moontlikheid dat Psalm 117 'n fragment van 'n groter geheel is, nooit regtig ondersoek nie.

\subsection{Tekskritiese opmerkings}

Daar is net een tekskritiese kwessie wat aandag vra. Die redakteurs van Biblia Hebraica Stuttgartensia stel voor dat volke (האִֶּים) verander moet word om העִכִים te lees - die alef word verander na 'n ajin. Die begrip umah kan egter vertaal word met "volk" of "stam" soos dit inderdaad in Numeri 25:15 gevind word. Om hierdie rede is daar geen noodsaak om die lesing te verander soos wat voorgestel is nie. Dahood (1970:152) emendeer ummim na enim' om dan vertaal te word as "gode" of "gevreesdes" na aanleiding van Jeremia 1:38. Soos later aangetoon sal word, vorm vers 1 'n sinonieme parallelisme wat versteur sou word indien die emendasie van Dahood aanvaar word.

\section{4 'n Ondersoek na die strukturele opbou van die psalm}

Psalm 117 het 'n eenvoudige opbou wat nie moeilik is om raak te sien nie:

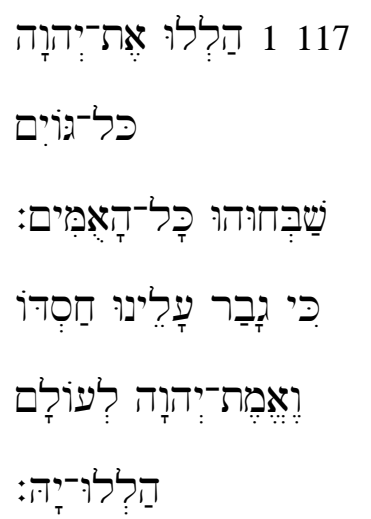

Daar is drie stylfigure in die psalm. Die psalm open en sluit met ' $n$ oproep om Jahwe te prys. Met die inclusio-stylfiguur word die psalm dus in 'n eenheid saamgebind. Vers 1 vorm 'n sinonieme parallelisme waarin die nasies en volke opgeroep word om Jahwe te loof en 
te prys. Vers 2 vorm 'n chiasme: (A) Groot/geweldig oor ons (is) (B) sy (verbonds-)liefde. (B) en die trou van Jahwe (is) (A) vir altyd. Terwyl die eenheid van die psalm deur die inclusio bevestig word, beklemtoon die twee stylfigure ook twee aksente in die psalm. Dit handel enersyds oor nasies en volke wat opgeroep word tot lof aan Jahwe, maar andersyds handel dit oor "ons" wat Jahwe se liefde en trou ervaar het. Seybold (1996:456) praat van 'n oproep tot lof gevolg deur 'n begronding van die lof (Lobaufruf und Lobbegrün$d u n g$ ). Die redegewende ki ('; "want") is belangrik. Die redegewende partikel lui die rede in waarom nasies en volke opgeroep word om Jahwe te prys. Die partikel $k i$ bind dus ook die twee dele van die psalm aan mekaar. Terwyl die parallelisme en die chiasme stylfigure is wat die twee dele van die psalm van mekaar onderskei, word die twee gedeeltes aan mekaar verbind deur die redegewende "want" aan die begin van vers 2 .

Daar is ook ander moontlikhede in terme van die strukturele opbou van die psalm waaraan aandag gegee kan word. Dit is ook moontlik om 'n chiastiese opbou in die psalm as geheel raak te sien: Halleluja $(A)$, die nasies en die volke (B); die liefde en trou van Jahwe (B), Halleluja (A). Beswaar teen hierdie standpunt is dat dit nie goed begryp word hoe en in watter mate die B-gedeeltes van die psalm met mekaar korreleer nie. Dahood (1970:152) het 'n chiasme opgemerk in die gebruik van die Godsnaam, Jahwe, wat in versreël 1 en 4 voorkom en die pronominale suffikse ("loof Hom"; "sy verbondsliefde") verwysende na Jahwe in versreëls 2 en 3. 'n Beswaar teen die standpunt van Dahood is dat die "hallelujah" waarmee die psalm afgesluit word, gewoon buite rekening gelaat word. Allen (1983:117) het die assonansie tussen gbr (גבר) en gjm (גוֹ) (אים) en

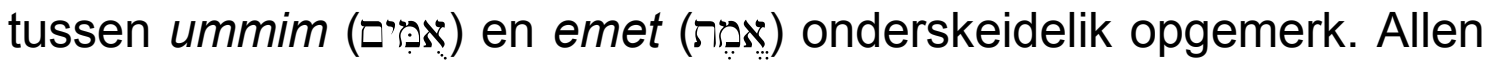
se waarneming versterk die eenheid van die psalm soos reeds deur die voorkoms van die redegewende "want" aan die begin van vers 2 aangetoon is.

\subsection{Die literêre genre van die psalm}

Wat is die soort literatuur (Gattung) wanneer Psalm 117 gelees word? Die psalm word gesien as ' $n$ himne wat aan Jahwe gerig is waar selfs vreemde nasies opgeroep word om Hom te prys. Dit is moontlik dat die persone wat die oproep gehoor het, geantwoord het met die woorde van vers 2 (Lamparter, 1959:252-253). Die imperatiewe vorms, die adressante, die vokatief, die partikel ki (כ) en die werkwoorde in die perfektum is alles aanduidings van die Gattung van 'n himne wat gebruik word (Anderson, 1972:795; Seybold, 
1996:456; Jeremias, 2004:95; Kraus, 1972:798; Allen, 1983:117; Vos, 2009:3-4).

Die tipiese situasie of Sitz im Leben is waarskynlik 'n kultiese een waar priesters of ander kultiese personeel die gewone mense ontmoet het waar hulle gekom het om te aanbid. Volgens Weiser (1975:721) moet die psalm gesien word as 'n oproep aan die mense aan die begin van 'n aanbiddingsgeleentheid om ' $n$ himne van lof aan Jahwe te sing.

Die vraag na die Sitz im Leben is ook 'n vraag na die historiese plasing van die gedeelte wat ondersoek word. Om 'n spesifiek historiese situasie nader aan die psalm te koppel, is problematies. Geleerdes is in die algemeen ook huiwerig om 'n spesifieke historiese situasie aan die psalm te verbind (Dahood, 1970:152), waarskynlik omdat daar min of geen direkte historiese aanduidings in die teks self te vind is. Dit sou veilig wees om met twee historiese situasies rekening te hou. Dit is moontlik om die psalm teen die agtergrond van die ballingskap te lees. Die verwysing na die vreemde nasies mag 'n aanduiding wees van die kontak wat Juda in die ballingskap met vreemde nasies gehad het. Die verwysing na vreemde nasies sou ook in verband gebring kon word met die teologiese oortuigings wat weerspieël word in byvoorbeeld Jesaja 40-55 (Lamparter, 1959:252-253; Burden, 1991:165; Mays, 1994: 373). Interessant genoeg is hierdie 'n standpunt wat B. Duhm as 'n moontlikheid genoem het (cf Lamparter, 1959:253; Kraus, 1972: 799). Kores, die Persiese heerser, word as Jahwe se messias gesien (Jes. 45:1). In die eerste kneglied (Jes. 42:1-9) ontvang die volk die opdrag en roeping om 'n lig vir die nasies te wees. In Jeremia 25:9 en ook 27:6 word die Babiloniese heerser as 'n dienaar in Jahwe se diens gesien wat die doel wat Jahwe het, moet vervul (Brueggemann, 2008:252). Ook in Jeremia 29:7 word die volk aangemoedig om die vrede en voorspoed van die stad te soek waarheen hulle in ballingskap weggevoer is. Dit is hierdie positiewe ingesteldheid teenoor die nasies in die eksiliese profetiese literatuur en die positiewe oproep na die nasies en volke om Jahwe te loof en te prys, wat 'n eksiliese agtergrond vir die psalm ' $n$ moontlikheid maak. Waarskynlik moet ' $n$ laat-eksiliese datum oorweeg word (teenoor Dahood, 1970:152 wat die psalm gedurende die sewende eeu v.C. dateer). $\mathrm{Na}$ die aanvanklike skok van die ballingskap, weerspieël in die klaagpsalms wat met die ballingskaptydperk verbind word (Ps. 74; 137), het daar nou 'n nuwe perspektief gekom om as volk van God in vreemde omstandighede te leef. Nou kan 'n oproep tot lof aan God gemaak word. 
Dit is egter ewe moontlik om 'n na-eksiliese datering vir die psalm te aanvaar. Allen (1983:117) verwys na Arameïsmes in die psalm wat 'n aanduiding sou wees van 'n na-eksiliese datering. So byvoorbeeld is dit die argument van Wagner (1966:111) dat sbh (שבח) waarskynlik 'n Arameïsme is en volgens Gunkel is ummim (האִֵֶים) 'n term wat sewe keer in bybelse Aramees voorkom en wat dus 'n aanduiding is vir 'n laat datering (vgl. Allen, 1983:116). Dahood (1970:152) bevraagteken egter die Arameïsmes en kom tot die gevolgtrekking dat die argument van die veronderstelde Arameïsmes nie gebruik kan word nie. Vir Goulder (1998:181) is die verwysing na Jahwe se genade (חיֶד) 'n verwysing na die verlossing uit die ballingskap. 'n Belangrike argument ten gunste van 'n na-eksiliese datering van Psalm 117 lê in die feit dat die psalm deel is van die sogenaamde Egiptiese Hallel psalms (Ps. 113-118) wat normaalweg na-eksilies gedateer word (Goulder, 1998:17).

Die twee moontlikhede hoef nie wedersyds uitsluitend te wees nie. Dit mag moontlik wees dat Psalm 117 aanvanklik in 'n laat-eksiliese tyd ontstaan het en later deel geword het van die Hallel-psalms binne 'n na-eksiliese konteks.

\subsection{Tradisiemateriaal in die psalm}

Daar is min of geen aanduidings van die voorkoms van die bekende heilstradisies in die psalm. Die eienskappe van Jahwe waarna in vers 2 verwys word, laat 'n mens dink aan die Sinaigebeure waar die verbondsluiting tussen Jahwe en sy volk plaasgevind het. Dit is immers by Sinai waar Jahwe Hom as die God van (verbonds)liefde en trou (Eks. 34:6) openbaar het. חדסד is 'n begrip wat dikwels in die $\mathrm{Ou}$ Testament voorkom met 'n verskeidenheid betekenisnuanses waaronder ook een van (verbonds)liefde. Jahwe se wֶ: is 'n begrip wat die idee van Jahwe se ewige trou weergee en dit is 'n term wat dikwels in die Ou Testament voorkom. Die goue kalfepisode (Eks. 32-34) het waarskynlik vir die volk in die ballingskap- en ook in die na ballingskaptyd die versekering gegee dat die verbond ná die gebeure van die ballingskap nog steeds van krag bly soos ook die verbond destyds by Sinai van krag gebly het. Soos die volk destyds die liefde en trou van Jahwe ervaar het, selfs na die goue kalfepisode, kan hulle ook weer ná die ballingskap 'n verwagting hê om Jahwe se liefde en trou te ervaar.

Die byeenbring van die vreemde nasies en die volk van God in een klein psalm, bring ook 'n ander perspektief na vore. In hierdie psalm word twee prominente lyne wat in die Ou Testament te vind is, saam 
gevind. Jahwe is aan die een kant die God van sy volk, maar Hy is ook God van alle nasies. Hierdie twee lyne word in die Abrahamsverhale gevind waar Abraham 'n groot nageslag belowe word, maar waar hy tegelykertyd ook 'n seën vir die nasies moet wees. In Eksodus 19 word Israel geroep om 'n nasie van priesters te wees, maar tegelykertyd word hulle daaraan herinner dat die hele aarde aan Jahwe behoort (Eks. 19:5; Brueggemann, 2008:249).

\section{3. 'n Peiling van die teologiese boodskap van Psalm 117}

Psalm 117 open met 'n oproep aan die nasies en volke om Jahwe te prys en te loof. In vers 2 word die rede vir die oproep tot lof gegee:

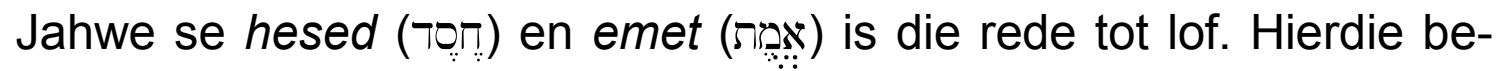
grippe kan teruggevoer word na die Sinaigebeure (Eks. 34:6) waar Jahwe Homself as die God van hesed en emet openbaar het, selfs na die verwoestende gebeure van die goue kalf. Dat juis hierdie tradisie in herinnering geroep word, dien om die volk te herinner dat die verbondsverhouding nog steeds daar is ten spyte van die gebeure van die ballingskap. In Psalm 117 word die lojale verbondsliefde en ewigdurende trou spesifiek gerig aan "ons", die huidige hoorders/lesers (Juda as die volk van God). Jahwe se liefde en trou was die ervaring van die volk in die verlede. Wanneer hulle nou weer die liefde en trou van Jahwe gaan ervaar, gaan dit 'n getuienis aan die nasies en volke wees en dit gaan hulle beweeg tot lof aan Jahwe vir dit wat Hy vantevore gedoen het en ook nou weer gaan doen in die geskiedenis van sy volk. Die huidige omstandighede van die ballingskap het die volk die verlede in herinnering laat roep en dit het ' $n$ verwagting na 'n toekomstige belewenis van Jahwe se liefde en trou gegee (in teenstelling met Kraus, 1972:798 wat 'n eskatologiese visie van die toekoms in die teks ontken).

Hierdie herinnering aan Jahwe se liefde en trou, steeds binne die ruimte van die verbond, is ' $n$ oproep om ook in 'n politeïstiese omgewing van 'n vreemde land steeds Jahwe te aanbid as die een en enigste God. God is inderdaad die "hoogste God", die Koning en Here van die wêreld (Kraus, 1972:789). Jahwe se liefde en trou roep ook hier die liefde en trou van die volk op teenoor Jahwe. Die volk was/is die passiewe ontvangers van Jahwe se liefde en trou en word opgeroep om aktiewe weerkaatsers van sy liefde en trou te wees, op so 'n wyse dat dit selfs ander nasies en volke tot lof aan Jahwe sal beweeg. Met inagneming van die onbelangrike rol wat 'n volk in ballingskap speel, is hierdie oproep des te meer merkwaardig. 
Dit is verder merkwaardig dat die psalm ook in die Nuwe Testament weerklank vind. In Romeine 15:11 word Psalm 117 as skriftuurlike bewys aangehaal dat God se doel in en met Jesus Christus die redding van alle mense is. Lekkerkerker (1975:175) merk op “... de heidenen word mede betrokken in het verheerlijken van God om zijn ontferming". Die messias het inderdaad Israel en die nasies gebring tot die gemeenskaplike lof aan God. Dit het Christus gedoen deur sy bereidheid om albei groepe aan te neem en hulle dienskneg te word (Jonker, 1976:189). Vanuit hierdie perspektief transendeer die ervaring van God se lojale liefde en trou die grense van nasionaliteit, kultuur en etnisiteit, omdat almal uiteindelik opgeroep word om in die lof aan God te deel.

Homileties is dit sinvol om die ryk betekenis van die twee teologiese sleutelbegrippe uit te lê en te verduidelik. Jahwe se verbondsliefde en trou bly geld selfs ná die afskuwelike oortreding met die goue kalf in Eksodus 32. Gelowiges kan dus verseker wees dat Jahwe se liefde en trou ook ten spyte van die ballingskap nie tot 'n einde gekom het nie. Dit skep die verwagting van 'n nuwe ervaring van Jahwe se liefde en trou wat inderdaad gerealiseer het in die gebeure rondom die terugkeer uit die ballingskap. Gelowiges wat die passiewe ontvangers van Jahwe se liefde en trou is, word ook die aktiewe weerkaatsers daarvan, sodat selfs ander vreemde volke Jahwe daarvoor loof. Dit is waarskynlik nie vergesog om te beweer dat ook die vreemde volke mettertyd ingetrek moet word om deel te word van die volk van God en self ook die liefde en trou van Jahwe te ervaar nie. Waar mense deel word van dieselfde geloofsgemeenskap word grense van klas, nasionaliteit, ras en etnisiteit oorskry.

'n Laaste opmerking: miskien het die beperkte omvang van die psalm ook iets te sê in terme van die boodskap. Daar is situasies waar min ander dinge gesê kan word as net 'n mondelinge herinnering aan en 'n aktualisering van Jahwe se liefde en trou.

\section{Gevolgtrekking}

Dit bly ' $n$ verrykende ervaring om 'n Bybelteks noukeurig te lees. Hierdie klein mini-psalm is nie net literêr gesproke 'n onafhanklike psalm in eie reg nie, maar die psalm het ook 'n eie teologiese boodskap tot verryking van geloofsgemeenskappe in die (verre) verlede en ook in die hede. Gelowiges (van destyds en vandag) was/is die passiewe ontvangers van Jahwe se liefde en trou. Hulle is egter die aktiewe weerkaatsers van Jahwe se liefde en trou tot so 'n mate dat dit ander nasies tot lof aan Jahwe sal bring. 


\section{Geraadpleegde werke}

ALLEN, L.C. 1983. Psalms 101-150. Word Books: Waco. (Word Biblical Commentary, 21.)

ANDERSON, A.A. 1972. The book of the Psalms: Vol. 2: Psalms 73-150. London: Oliphants. (New Century Bible.)

BIBLIA HEBRAICA STUTTGARTENSIA. 1990. Biblia Hebraica Stuttgartensia. Stuttgart: Deutsche Bibelgesellschaft.

BRUEGGEMANN, W. 2008. Old Testament theology - an introduction. Nashville: Abingdon. (Library of Biblical Theology.)

BURDEN, J.J. 1991. Psalms 101-119. Kaapstad: NG Kerkuitgewers. (Skrifuitleg vir Bybelstudent en gemeente.)

DAHOOD, M. 1970. Psalms 101-150: a new translation with introduction and commentary. New York: Doubleday \& Compay. (Anchor Bible, 17A.)

GOULDER, M.D. 1998. The psalms of the return. Vol. 5: Psalms 107-150. Sheffield: Sheffield Academic Press. (Journal for the study of the Old Testament Supplement Series 258.)

KRAUS, H.J. 1972. Psalmen. 2. Teilband: Psalmen 64-150. Neukirchen-Vluyn: Neukirchener Verlag. (Biblischer Kommentar zum Alten Testament 15/2.)

JEREMIAS, J. 2004. Worship and theology in the psalms. (In Human, D.J. \& Vos, C.J.A., eds. Psalms and liturgy. London: Clark. p. 89-101.) (Journal for the Study of the Old Testament Supplement Series 410.)

JONKER, W.D. 1976. Die brief aan die Romeine. Kaapstad: NG Kerkuitgewers.

LAMPARTER, H. 1959. Das Buch der Psalmen. 2. Bd.: Psalmen 73-150. Stuttgart: Calwer. (Botschaft des Alten Testament, 15.)

LEKKERKERKER, A.F.N. 1975. De brief van Paulus aan de Romeinen. Bd. 2. Nijkerk: Callenbach. (De prediking van het Nieuwe Testament.)

MAYS, J.L. 1994. Psalms. Louisville: John Knox. (Interpretation.)

SEYBOLD, K. 1996. Die Psalmen. Tübingen: Mohr \& Siebeck. (Handbuch zum Alten Testament, 1/15.)

STOEBE, H.J. 1971. Güte - haesed. (In Jenni, E. \& Westermann, C., Hrsg. Theologisches Handwörterbuch zum Alten Testament. Band 1. München: Kaiser Verlag. S. 600-621.)

VOS, C.J.A. 2009. The psalms as hymns in a liturgical context. HTS, 65(1): Art. 105, 6 pages. (DOI:10.4102/hts.v65i.105.)

WAGNER, M. 1966. Die lexikalischen und grammatikalischen Aramaismen in alt Hebräisch. Berlin: Töpelmann. (Beihefte Zeitschrift für die Alttestamentliche Wissenschaft, 96.)

WEISER, A. 1975. The psalms: a commentary. London: SCM. (Old Testament Library.).

WILDBERGER, H. 1971. Emet. (In Jenni, E. \& Westermann, C., Hrsg. Theologisches Handwörterbuch zum Alten Testament. Band 1. München: Kaiser. S. 202-210.)

\section{Kernbegrippe}

prys

trou

verbondsliefde 


\section{Key concepts}

faithfulness

praise

steadfast love 
